\title{
Fibrin Sealant and Femtosecond Laser Assisted Keratoplasty: Initial Results
}

\section{Tatiana MB Prazeres ${ }^{1 *}$, Elissandro MS Lindoso1, Leon Grupenmacher ${ }^{2}$ and Luciene B Sousa ${ }^{3}$}

${ }^{1}$ Clinical Fellow, Cornea and External Diseases Division, Department of Ophthalmology, Sorocaba Eye Bank, Sorocaba, Sao Paulo, Brazil ${ }^{2}$ Attending Physician, Department of Ophthalmology, Sorocaba Eye Bank, Sorocaba, Sao Paulo, Brazil

${ }^{3}$ Head Professor of the Department of Ophthalmology, Sorocaba Eye Bank, Sorocaba, Sao Paulo, Brazil

\begin{abstract}
Purpose: To evaluate whether the use of a sealant combined with interrupted suture would provide better visual outcomes and better post-operative recovery to keratoconic patients compared to interrupt and running sutures without the use of sealants using femtosecond laser assisted keratoplasty.
\end{abstract}

Methods: A prospective, randomized study of 12 patients (12 eyes) with keratoconus was conducted, randomized into two treatment groups. The no glue group (6 eyes) underwent penetrated keratoplasty (PK) with femtosecond laser assisted keratoplasty shaped (mushroom) and combined suture (8 interrupted suture and 8 running sutures) while the glue group ( 6 eyes) underwent the same procedure but their incisions were closed with 8 interrupted sutures and sealant.

Results: The no glue group had a mean BCVA of 0.2 (LogMar). The glue group had a mean BCVA of 0.3 (LogMar). $p=0.028$ Transplants with glue were well positioned showing good healing but presented more inflammation in the first week post-surgery. Regarding refractive outcomes, there was no difference between the groups.

Conclusions: There were no statistical difference between the two groups regarding BCVA and refractive errors. The use of sealants produced more inflammation. Further studies with a larger number of patients and longer follow up would be needed to confirm these findings.

Keywords: Fibrin sealant; Penetrating keratoplasty; Femtosecond laser; Interrupted sutures; Running sutures

\section{Introduction}

Traditional PK provides excellent results for patients with significant visual loss due to corneal disease but visual rehabilitation is often prolonged [1]. Post-keratoplasty astigmatism is one of the major problems caused by PK that may compromise the patient's visual rehabilitation after surgery [2]. The astigmatism that occurs following PK may be caused by several reasons, including previous pathologies present in the donor or in the recipient, imprecise trephination, donorrecipient wound disparity, improper suture placement, unequal suture tension, and irregular wound healing [3].

In the past decades, PK surgery has undergone continuous improvements. A number of instruments have been developed to improve the quality of trephination in both donor and recipient corneas, and countless suturing techniques have been used to reduce tissue distortion and minimize postoperative refractive errors [4].

Suturing techniques such as single continuous suture, interrupted suture or combined continuous and interrupted suture have been used. Erosions, infiltrates, infectious keratitis related to sutures, loose sutures, wound leak, broken sutures and wound dehiscence following suture removal are some of the suture-related complications that frequently occur after PK, as described by many authors [5-7]. Thus, a procedure for corneal transplantation that minimizes the complications related with sutures is needed.

Fibrin sealants are surgical haemostatic and adhesive agents derived from blood plasma. These agents are designed to reproduce the final steps of the physiological coagulation cascade and to form a stable fibrin clot. Once formed, the fibrin clot stops the bleeding and aids normal wound healing [8].

Beriplast $^{\circledR} \mathrm{P}$ (Aventis Behring, Marburg, Germany) is a sealant that has been available in Japan and Europe for many years. Its use in a broad range of surgeries is well documented and the sealant has an excellent safety profile [9].

In ocular surgery, Beriplast ${ }^{\circledR} \mathrm{P}$ can be used to seal perforations, to treat conjunctival wounds and fistulas, to adapt free skin transplants in lid surgery, to repair injured canaliculi and to seal the wound in cataract surgery, pterygium, and strabismus surgeries [10,11]. Recently, the use of fibrin glue was applied to automated lamellar therapeutic keratectomy concluding it can provide safe and effective attachment needed in automated lamellar therapeutic keratectomy and obviates the need for suturing. [12] The use of fibrin sealants has been described in an ex-vivo eye model for opposing wound edges in Top Hat PKP [13] but no description of its use in vivo in PK has been done.

In this study we evaluated whether the use of a sealant combined with interrupted suture would provide better visual outcomes and postoperative recovery to keratoconic patients compared to interrupted and running sutures without the use of sealants.

\section{Methods}

This study was performed in the Sorocaba Eye Bank, in Sao Paulo, Brazil. We performed a randomized, prospective, case control clinical trial that involved 12 patients (12 eyes) who presented the diagnosis of keratoconus. Patients in both groups had keratoconus grade three

*Corresponding author: Tatiana Prazeres MB, Rua Conselheiro Correa de Menezes, n266, Apt 701, Salvador, Bahia, Brazil, Tel: 55-71-3334-3084/ 55-71 8799-3084; E-mail: tatianaprazeres@hotmail.com

Received January 26, 2012; Accepted July 12, 2012; Published July 14, 2012

Citation: Prazeres TMB, Lindoso EMS, Grupenmacher L, Sousa LB (2012) Fibrin Sealant and Femtosecond Laser Assisted Keratoplasty: Initial Results. J Transplant Technol Res 2:112. doi:10.4172/2161-0991.1000112

Copyright: @ 2012 Prazeres TMB, et al. This is an open-access article distributed under the terms of the Creative Commons Attribution License, which permits unrestricted use, distribution, and reproduction in any medium, provided the original author and source are credited. 
and four according to the topographic image based classification of Rabinowitz [14]. All patients were informed about the procedure and provided informed consent. This study was approved by the ethics committee of the Sorocaba Eye Hospital.

A total of 12 patients were randomized into two treatment groups. The first group (no glue group) was comprised of 6 patients (6 eyes) and underwent PK with femtosecond laser (IEK) shaped (mushroom) incisions that were closed with 8 interrupted and 8 running sutures. The second group (glue group) also included 6 patients ( 6 eyes) who underwent the same surgery as the no glue group but their incisions were closed with 8 interrupted sutures and sealant.

Peribulbar anesthesia was performed in all patients. The recipient intralase cut size was $8.0 \mathrm{~mm}$ and the donor intralase cut size was 8.25 $\mathrm{mm}$. In the glue group, the sealant was applied using the pantajet ${ }^{\mathbb{R}}$ syringe over the lamellar tissue (dual way) after the anterior chamber was filled a $06 \mathrm{~mm}$ air bubble. When the procedure was finished, a bandage contact lens was applied along with a subconjuntival injection of dexamethasone $0.1 \%$ and gentamicin $20 \mathrm{mg}$ in both groups. Patients were followed-up at 1 month, 3 months, and 6 months post-surgery.

The sealant used was approximately $1 \mathrm{~mL}$ of Beriplast (Behring). All procedures were performed by the same surgeon. For the postsurgery, patients were prescribed monofloxacin eye drops four times a day for 7 days and eye drops of prednisolone acetate $1 \%, 8$ times per day for a week and then tapered.

The outcomes measured included the best-corrected visual acuity (BCVA), manifest refraction, slit lamp examination to measure the degree of inflammation by the flare in the anterior chamber, intraocular pressure, corneal topography, pachymetry, optical coherence tomography, and specular microscopy.

The statistical analysis was performed with the Software Statistical Package for Social Science (SPSS) version 11.0. $\mathrm{P}<0.05$ was considered statistic significant.

\section{Results}

Patients were evaluated six months after surgery. Regarding the BCVA, the two groups presented no difference during the first month post-surgery $(p=0,730)$ but the no glue group presented better BCVA than the second group $(\mathrm{p}=0.005)$ in the sixth month after surgery (Chart 1).

As for refractive outcomes, the two groups presented no difference for spherical correction and cylinder (Chart 2).

No statistical differences between groups were observed for specular microscopy $(\mathrm{p}=0,572)$ and cornea thickness $(\mathrm{p}=0,043)$ (Chart 3 and 4$)$.

The OCT (optical coherence tomography) visant could be performed in both groups; with the glue group showing well-positioned button and good healing (Figure 1).

We also observed some complications. One patient from the glue group presented seidel after one week and another patient presented peripheral edema associated with a persistent epithelium defect, but with no elevation of the graft at the graft-host junction or surface irregularities. The completed epithelialization of the cornea in this case occurred after fourteen days of post operative with no additional treatment. Also, patients from the glue group presented more inflammation in the first day following the surgery. We could observe the presence of flare (16-25 cells in field-2+) [15] in the anterior

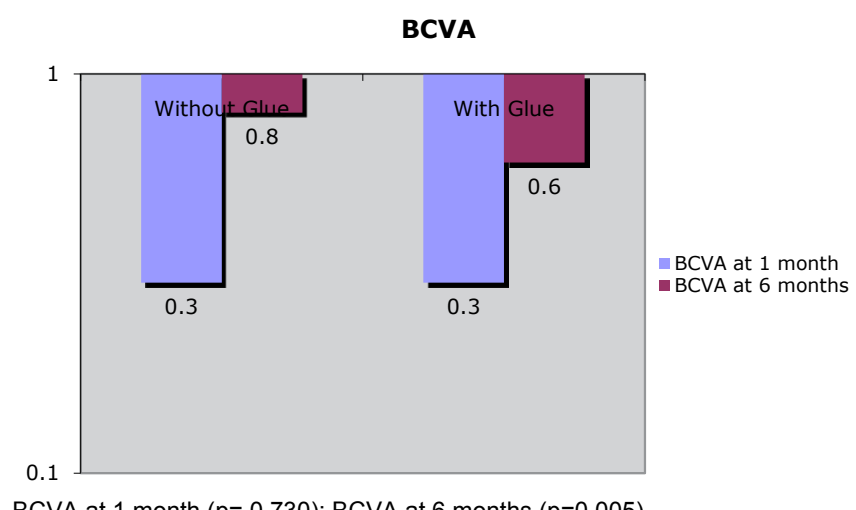

BCVA at 1 month $(p=0,730)$; BCVA at 6 months $(p=0,005)$

Chart 1: Mean Best Correct visual acuity in IEK with glue and IEK without glue in 1 month and 6 months (LogMar)

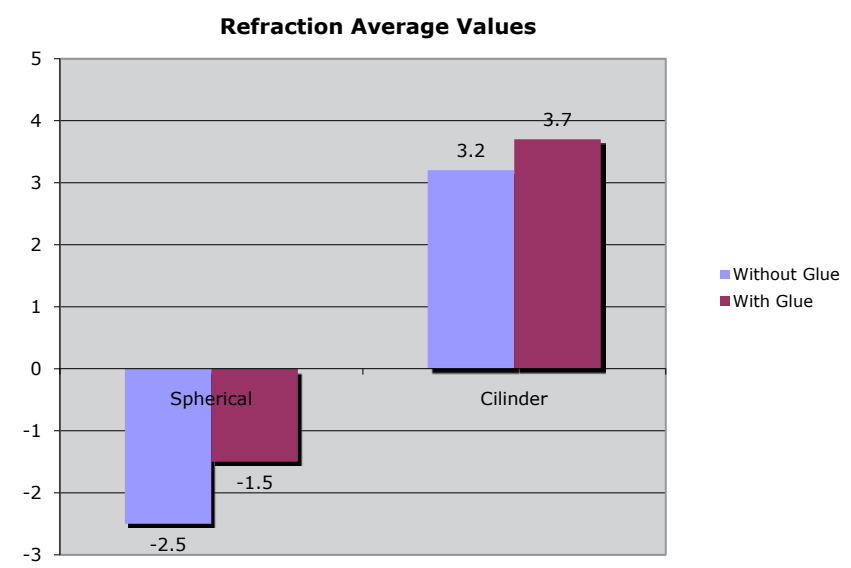

Chart 2: Refraction average values in IEK with glue and IEK without glue $(p=$ $0,419 / p=0,463)$

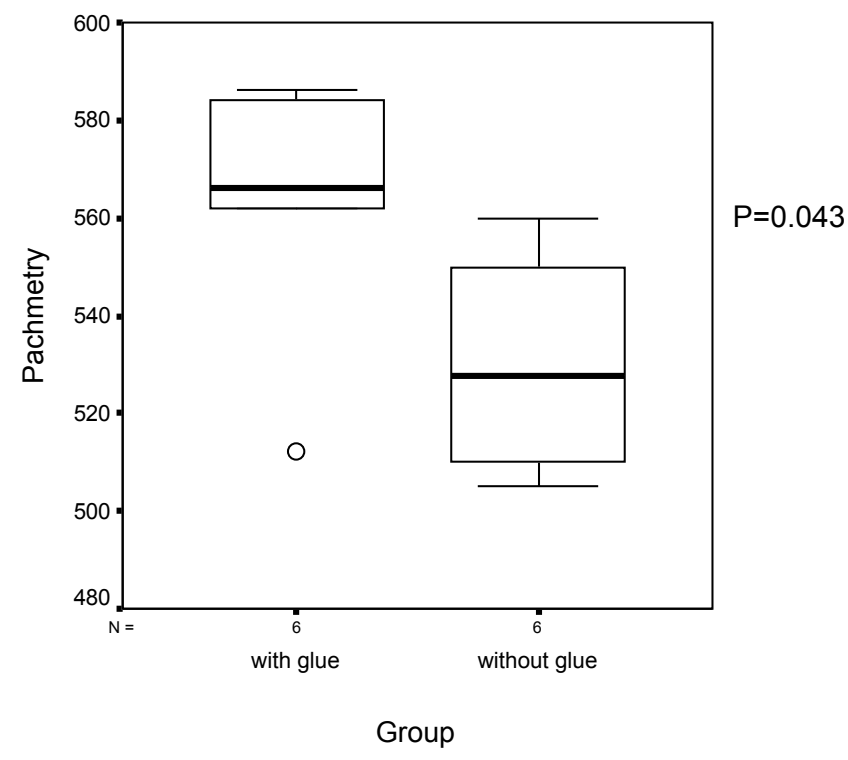

Chart 3: Pachmetry Boxplot. 


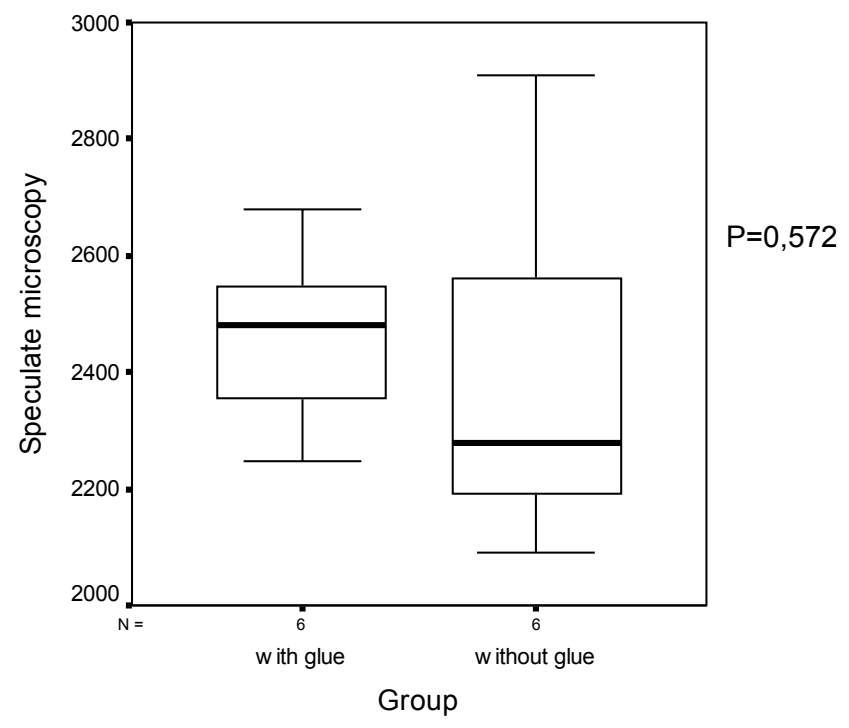

Chart 4: Speculate microscopy boxplot.

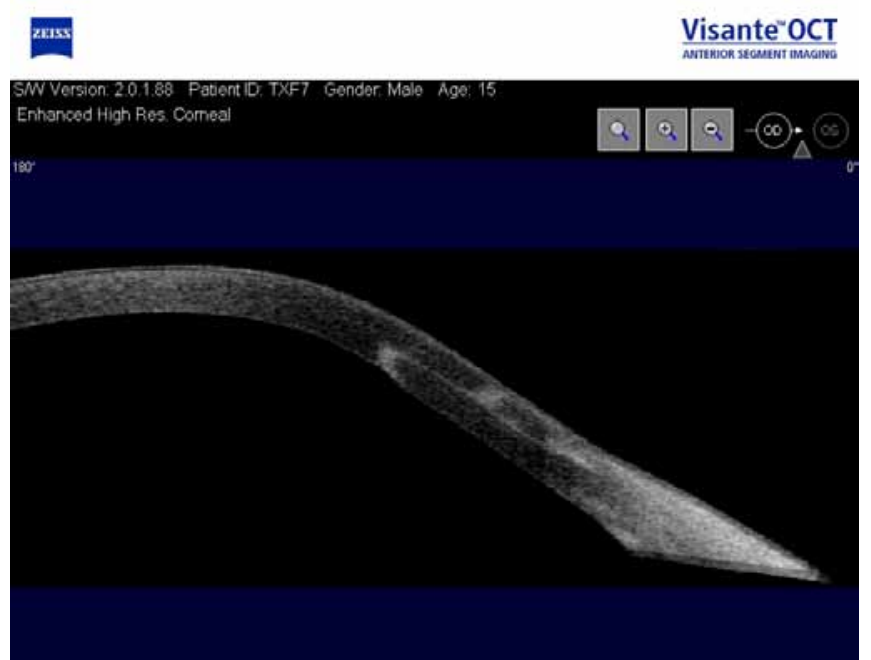

Figure 1: Anterior Segment Imaging of the wound incision after placement of 8 sutures and fibrin glue at six months.

chamber only in the glue group. And we did not observe the presence of the glue in the anterior chamber.

\section{Discussion}

A number of novel transplant techniques, including the descemet strip keratoplasty and posterior lamellar keratoplasty procedures, may offer significant advantages over traditional PK. Nevertheless, they cannot address the full range of corneal pathologic features. Additionally, they also present their own unique limitations $[1,16,17]$. Thus, improving the PK technique, especially in terms of visual rehabilitation, is needed to obtain better visual results and a shorter postoperative recovery.

A frequent major limitation of visual rehabilitation associated to $\mathrm{PK}$ is the high levels of post-operative astigmatism, which often requires selective suture removal or that secondary procedures are performed (after all sutures are removed). The mean refractive astigmatism observed six months after surgery was 3.2 in the no-glue group and 3.7 in the glue group. No suture was removed or adjusted until the sixth month post operatory. After this period, selective sutures were removed depending on the refraction.

Buratto et al. [1], found the mean refractive astigmatism of $2.9 \mathrm{D}$ three months after surgery using either interrupted suture or a mixture of interrupted and continuous running suture.

The Femtosecond laser technology enables that single and unique sizes and shapes of corneal cuts are performed, according to surgical needs. PK can be safely and precisely performed [18]. The sutures needed for the mushroom technique may not be as tight as that for the traditional PK because the sutures are placed aiming to hold the donor button in place and not necessarily to prevent wound leakage. We found that femtosecond laser with interrupted suture and running suture leads to better visual acuity in the first six months, as compared to application of interrupted suture plus glue.

Bahar et al. [13], in a laboratory study in ex-vivo eyes compared among traditional PKP, Top Hat PKP+sutures, and Top Hat PKP+glue and found that similar rates of astigmatism were induced by either technique. The group also showed that the Top Hat + glue used with 8 sutures is more watertight and stable than traditional PKP and Top Hat $\mathrm{PKP}+16$ sutures. In our model we didn't analyze the wound bursting pressure.

In the present study, we were able to observe more inflammation in the early post operative of the glue group. The anterior chamber was filled with air in both groups, so do not attribute this to the increased inflammation in the glue group.

Other studies using fibrin sealant in ocular surface surgery and strabismus showed a reduction in inflammation in the post-operatory. Causes of inflammation such as surgical trauma can be responsible for this $[19,20]$.

In this study we found that the use of fibrin sealant associated with interrupted sutures, instead of running sutures associated with interrupted sutures, produced more inflammation on the early postoperative and also produced worse corrected visual acuity. Thus, improved suturing techniques are needed to optimize visual outcomes and to control induced astigmatism.

\section{Conclusion}

We found that the association of fibrin sealant with interrupt sutures, instead of running sutures associated with interrupt sutures caused more inflammation on the early post-operative and also produced a worse corrected visual acuity. Although the procedure required shorter surgery times, it produced refractive errors similar to those observed with $\mathrm{PK}$ with the advantage of not presenting endothelial cell loss.

Further studies with a larger number of patients and longer follow up would be needed to confirm these findings.

\section{References}

1. Buratto L, Bohm E (2007) The use of Femtosecond Laser in penetrating Keratoplasty. Am J Ophthalmol 143: 737-742.

2. Lee GA, Pérez-Santonja JJ, Maloof A, Ficker LA, Dart JK (2003) Effects of lamellar keratotomy on postkeratoplasty astigmatism. Br J Ophthalmol 87: 432 435. 
Citation: Prazeres TMB, Lindoso EMS, Grupenmacher L, Sousa LB (2012) Fibrin Sealant and Femtosecond Laser Assisted Keratoplasty: Initial Results. J Transplant Technol Res 2:112. doi:10.4172/2161-0991.1000112

3. Vajpayee RB, Sharma V, Sharma N, Panda A, Taylor HR (2001) Evaluation of techniques of single continuous suturing in penetrating keratoplasty. $\mathrm{Br} \mathrm{J}$ Ophthalmol 85: 134-138.

4. Busin M (2003) A New Lamellar Wound Configuration for Penetrating Keratoplasty Surgery. Arch Ophthalmol 121: 260-265.

5. Christo CG, van Rooij J, Geerards AJ, Remeijer L, Beekhuis WH (2001) Suture-related Complications following Keratoplasty: A 5-Year Retrospective Study. Cornea 20: 816-819.

6. Das S, Whiting M, Taylor HR (2007) Corneal Wound dehiscence after penetrating keratoplasty. Cornea 26: 526-529.

7. Vajpayee RB, Sharma N, Sinha R, Agarwal T, Singhvi A (2007) Infectious keratitis following keratoplasty. Surv Ophthalmol 52: 1-12.

8. Jackson MR, MacPhee MJ, Drohan WN, Alving BM (1996) Fibrin sealant: current and potential clinical applications. Blood Coagul Fibrinolysis 7: 737 746 .

9. Dunn CJ, Goa KL (1999) Fibrin sealant: A review of its use in surgery and endoscopy. Drugs 58: 863-886.

10. Koranyi G, Seregard S, Kopp ED (2004) Cut and paste: a no suture, small incision approach to pterygium surgery $\mathrm{Br} \mathrm{J}$ Ophthalmol 88: 911-914.

11. Basmak H, Gursoy H, Cakmak Al, Niyaz L, Yildirim N, et al. (2011) Tissue adhesives as an alternative for conjunctival closure in strabismus surgeries. Strabismus 19: 59-62.
12. Hashemi $H$, Daggostar A (2011) Automated lamellar therapeutic keratoplasty with fibrin adhesive in the treatment of anterior cornea opacities. Cornea 30 : 655-659.

13. Bahar I, Kaiserman I, Slomovic A, McAllum P, Rootman D (2007) Fibrin glue for opposing wound edges in "Top Hat" penetrating keratoplasty: a laboratory study. Cornea 26: 1235-1238.

14. Mannis MJ, Holland EJ (2005) Post-keratoplasty Astigmatism. In: Krachmer $\mathrm{JH}$, Cornea. Surgery of the Cornea and Conjunctiva. Mosby, Philadelphia 1527-1537.

15. Jabs DA, Nussenblatt RB, Rosenbaum JT, Standardization of Uveitis Nomenclature (SUN) Working Group (2005) Standardization of uveitis nomenclature for reporting clinical data: Results of the First International Workshop. Am J Ophthalmol 140: 509-516.

16. Randleman JB, Stulting RD (2006) Prevention and treatment of corneal graft rejection: current practice patterns (2004). Cornea 25: 286-290.

17. Javadi MA, Motlagh BF, Jafarinasab MR, Rabbanikhah Z, Anissian A, et al (2005) Outcomes of penetrating keratoplasty $n$ keratoconus. Cornea 24: 941 946.

18. Holzer MP, Rabsilber TM, Auffarth GU (2007) Penetrating Keratoplasty using femtosecond laser. Am J Ophtalmol 143: 524-526.

19. Pfister RR, Sommers $\mathrm{Cl}$ (2005) Fibrin sealant in corneal steam cell transplantation. Cornea 24: 593-598.

20. Biedner B, Rosenthal G (1996) Conjunctival closure in strabismus surgery: Vicryl versus fibrin glue. Ophthalmic Surg Lasers 27: 967. 